\title{
Mecanismos de gestão municipal e a promoção dos direitos humanos
}

\author{
Magda Cristina de Sousa \\ Universidade Federal Rural do Semiárido (Ufersa) / Departamento de Agrotecnologia e \\ Ciências Sociais \\ Mossoró / RN - Brasil
}

Patrícia Verônica Pinheiro Sales Lima

Universidade Federal do Ceará (UFC) / Programas de Pós-Graduação em Desenvolvimento e Meio Ambiente e Economia Rural

Fortaleza / CE - Brasil

Ahmad Saeed Khan

Universidade Federal do Ceará (UFC) / Programas de Pós-Graduação em Desenvolvimento e Meio Ambiente e Economia Rural

Fortaleza / CE - Brasil

\begin{abstract}
O objetivo da pesquisa consistiu em avaliar a implementação de mecanismos e ações para a promoção e garantia dos direitos humanos no âmbito da administração pública municipal. A descentralização do poder federal, intensificada a partir da Constituição Federal de 1988, trouxe novas atribuições para estados e municípios, com uma transferência de responsabilidades que influencia diretamente as políticas de direitos humanos. Nesse cenário de natureza neoliberal, observa-se um ambiente difuso onde as competências não são claras e emergem lacunas de conhecimento, especialmente sobre o papel do município na construção de uma sociedade inclusiva. A partir da análise de indicadores de gestão municipal publicados pelo Instituto Brasileiro de Geografia e Estatística foi possível traçar um panorama de gestão municipal dos direitos humanos no Ceará que evidenciou a omissão das prefeituras.
\end{abstract}

Palavras-chave: gestão municipal; direitos humanos; planejamento.

Mecanismos de gestión municipal y la promoción de los derechos humanos

El objetivo de la investigación fue evaluar la implementación de mecanismos y acciones para promover y garantizar los derechos humanos en el ámbito de la administración municipal. La descentralización del poder federal aumentó después de la Constitución Federal de 1988 y trajo nuevas responsabilida-

DOI: http://dx.doi.org/10.1590/0034-7612135619

Artigo recebido em 29 maio 2014 e aceito em 5 mar. 2015.

(cc) BY-NC

Rev. Adm. Pública - Rio de Janeiro 49(4):985-1009, jul./ago. 2015 
des a los estados y municipios, con una transferencia de responsabilidades que influye directamente en las políticas de derechos humanos. En este escenario de naturaleza neoliberal, hay un ambiente difuso donde las competencias no son claras y surgen lagunas de conocimiento, especialmente sobre el papel de la municipalidad en la construcción de una sociedad inclusiva. A partir del análisis de los indicadores de la gestión municipal publicados por el Instituto Brasileño de Geografía y Estadística fue posible dar una visión general de la gestión municipal de los derechos humanos en Ceará, que mostró la omisión de las prefecturas.

Palabras clave: gestión municipal; derechos humanos; planificación.

\section{Mechanisms of municipal management and promotion of human rights}

The research objective was to assess the implementation of mechanisms and actions to promote and guarantee human rights within the municipal public administration. Because of the decentralization of power, after the Federal Constitution of 1988, states and municipalities received new responsibilities. There was a transfer of responsibilities that influenced directly the human rights policies. In this scenario of neo-liberal nature, there is a too diffuse environment where competences are unclear and emerge gaps in knowledge, especially about the role of the municipality in building an inclusive society. From the analysis of indicators of municipal management published by the Brazilian Institute of Geography and Statistics, it was possible to draw an overview of municipal human rights management in Ceará that showed the omission of city halls.

Keywords: municipal management; human rights; planning.

\section{Introdução}

As competências dos governos municipais, embora mal definidas, foram ampliadas e ganharam maior atenção com a descentralização governamental caracterizada na Constituição Federal de 1988. Passadas mais de duas décadas, a nova situação institucional dos municípios ainda não provocou mudanças substanciais na promoção dos direitos humanos.

Os desafios identificados ante a temática em questão são vários. De acordo com Gershon, Alto e Souza (2005), os governos municipais não demonstram interesse suficiente para favorecer a institucionalização de políticas públicas de direitos humanos. Segundo os autores, a realidade observada nos municípios brasileiros requer avanços e reflexão sobre a urgente necessidade de adoção de instrumentos de gestão que favoreçam resultados mais efetivos no âmbito das políticas públicas de direitos humanos. Essa preocupação é pertinente e oportuna haja vista que a esfera municipal do governo é a mais indicada para a implementação de políticas públicas direcionadas à promoção dos direitos humanos e redução de desigualdades (Alves e Vasconcelos, 2005).

Em concordância com Cruz e colaboradores (2012:155), quando argumentam que "o município é o ente federativo mais próximo dos cidadãos e ao qual esses recorrem para suprir as principais demandas sociais", é natural atribuir à gestão pública municipal um papel de destaque na construção de um ambiente favorável à implementação dos direitos humanos. 
Parte dos problemas enfrentados na esfera municipal quanto à inserção da dimensão direitos humanos na agenda governamental se dá pela falta de clareza quanto às competências municipais. O papel da esfera municipal é assunto recorrente nas Conferências Nacionais sobre Direitos Humanos, a primeira delas ocorrida em 1996, mas não há uma estratégia concreta para "estimular e incentivar a atuação dos governos locais numa lógica de garantia e defesa dos direitos humanos" (Oliveira, 2001). Nesse contexto, a sistematização de informações quanto aos conselhos, comissões legislativas ou planos municipais e suas estratégias para a promoção dos direitos humanos surge como uma forma de identificar fragilidades a serem vencidas por meio de processos de tomada de decisão que servirão de alicerce para maiores e substanciais mudanças na gestão dos direitos humanos no âmbito local.

Este estudo assume como pressuposto que maiores níveis de adoção de instrumentos de gestão municipal de direitos humanos potencializam a efetividade de políticas públicas em âmbito local e dão suporte às políticas nacionais e estaduais. Nessa perspectiva, tem como objetivo avaliar a implementação de mecanismos e ações para a promoção e a garantia dos direitos humanos no âmbito da administração pública municipal no estado do Ceará. Trata-se de trazer à discussão a atuação do poder público local no âmbito das disposições da Constituição Federal de 1988, arts. 5o e 6º que tratam dos direitos humanos básicos dos cidadãos.

\section{Direitos humanos na perspectiva do direito}

Os direitos humanos nasceram da necessidade de defender e preservar as pessoas mais carentes e desassistidas que viviam à mercê da sua própria sorte, em oposição aos interesses do autoritarismo estatal. Vaz (2009:10) os define como "o conjunto de direitos e garantias que têm por finalidade básica o respeito à dignidade humana, por meio da proteção desta contra a ação arbitrária do Estado, e o estabelecimento de condições mínimas de vida humana digna que exigem prestações estatais positivas".

Os direitos humanos não são fenômenos, coisas dadas. Antes, são legados de lutas históricas. Uma construção erguida por meio de heróis e heroínas que tombaram, muitas vezes, antes mesmo de contentarem seus intentos. Após a Segunda Guerra Mundial em 1945, motivada principalmente pelas atrocidades cometidas em nome de ideologias fascistas e nazistas, uma nova era dos direitos se avizinha. O Tribunal de Nuremberg (1945-46) foi instalado com a finalidade de julgar os alemães pelas barbaridades cometidas no período da guerra. Criado pelo acordo de Londres de 1945, "não apenas consolida a ideia da necessária limitação da soberania nacional como reconhece que os indivíduos têm direitos protegidos pelo direito internacional". A criação da Organização das Nações Unidas (ONU) e a adoção da Declaração Universal dos Direitos Humanos pela Assembleia Geral da ONU, em 1948, redefinem os postulados da teoria do Estado e recolocam o "homem social" no centro das preocupações contemporâneas. Dessa forma, substitui-se a lógica da destruição pela arquitetura da cidadania internacional.

Rev. Adm. Pública - Rio de Janeiro 49(4):985-1009, jul./ago. 2015 
O valor máximo a ser perseguido passou a ser o da dignidade da pessoa humana como paradigma e referencial ético, verdadeiro superprincípio a orientar o constitucionalismo contemporâneo, nas esferas local, regional e global, doando-lhe especial racionalidade, unidade e sentido.

A Constituição de 1988 consagrou os direitos sociais no capítulo II do Título I, onde expressou em seu art. 6o: "são direitos sociais a educação, a saúde, a alimentação, o trabalho, o lazer, a segurança, a previdência social, a proteção à maternidade e a infância, a assistência aos desamparados, na forma desta constituição". Para Silva (1992), os direitos sociais têm dimensão de direitos fundamentais por se constituírem em prestações positivas sistematizadas nas constituições que asseguram melhores condições de vida aos mais vulneráveis, direito que tende a igualizar situações sociais desiguais.

Ao incluir o trabalho no rol dos direitos sociais (arts. 6ำ e 7으), o constituinte reforça a ideia do trabalho como dignidade da pessoa humana sem, no entanto, desconsiderá-lo da ordem econômica pois, como ensina Silva (1992), os direitos econômicos têm uma dimensão institucional, enquanto os direitos sociais constituem formas de tutela pessoal. O direito econômico regula as relações de mercado e o direito social existe a partir dele, para promover a justiça igualitária e equilibrar as relações tutelando a parte mais vulnerável da relação no mundo econômico.

Os direitos metaindividuais provenientes dos conflitos de massas, acentuados no pósguerra, ganham consubstancialidade a partir da necessidade processual de compô-los. Estudo elaborado por Moreira (1977) aponta que em 1965 o Brasil já possuía um instrumento processual de defesa dos direitos metaindividuais trazidos pela Lei no 4.717 — ou Lei da Ação Popular. A importância desse feito está na tutela dos interesses e direitos metaindividuais. Em 1985, a promulgação da Lei no 7.347 - Ação Civil Pública -, instrumento processual colocado a serviço da sociedade, traz um mecanismo de defesa contra a "lesão ou ameaça de lesão ao meio ambiente, ao consumidor, aos bens e direitos de valor artístico, estético, histórico e paisagístico" (Fiorillo, 2005:5).

Fiorillo (2005) relata que no respectivo projeto de Lei, em seu artigo 1ำ, IV, “a ação civil pública seria um instrumento apto à defesa, além dos direitos supracitados, de qualquer outro direito difuso e coletivo". Em que pese a falta de previsão legal, o presidente da República vetou o citado inciso, usando do mérito da falta de conteúdo no ordenamento jurídico que contemplasse os interesses e direitos difusos.

O legislador constituinte de 1988 findou por autorizar a tutela dos direitos individuais e não só reconheceu como também admitiu a tutela de direitos coletivos, considerando a existência de uma terceira geração de bem: o bem ambiental, no art. 225 — consagrando a existência de um bem que perpassa a esfera do público e do privado, um bem de uso comum do povo, o bem ambiental; o bem difuso.

Em 1990, em face da previsão constitucional do bem ambiental, é editada a Lei no 8.078, que tratou de definir em seu art. 81, parágrafo único, I, II e III, os direitos metaindividuais (direitos difusos, coletivos e individuais homogêneos, respectivamente), como também 
acrescentou o inciso IV do art. 1ํ da Lei ำ 7.437/1985 que outrora havia sido vetado, autorizando a utilização da Ação Civil Pública em defesa dos interesses e direitos difusos e coletivos.

Por conta do aludido preceito, o direito apresenta-se como um direito transindividual, tendo um objeto indivisível, titularidade indeterminada e interligada por circunstância de fato. Fiorillo (2005:8) lembra que o direito difuso é aquele que se encontra difundido pela coletividade, pertencendo a todos e a ninguém ao mesmo tempo. Os coletivos, por sua vez, possuem um traço característico: a determinabilidade dos seus titulares.

As subdivisões atribuídas aos direitos humanos explicitam sua abrangência e consequente importância na promoção e efetivação dos demais direitos. Nesse contexto, e sob a égide do princípio da prevalência dos direitos humanos (art. 4º, inciso II, CF 1988), espera-se dos governos federal, estadual e local a adoção de instrumentos que proporcionem à população a garantia de direitos humanos como condição para uma vida digna.

\section{Planejamento público municipal e a promoção dos direitos humanos}

Todas as ações governamentais voltadas para a efetivação dos direitos humanos requerem do poder público um planejamento estratégico. Planejamento é uma ferramenta de gestão. É um processo de organização de tarefas, com vistas a se atingir uma finalidade, com etapas características e sequências que, em geral, estão assim ordenadas:

Identificar o objeto do planejamento, criar uma visão sobre o assunto, definir o objetivo do planejamento, determinar uma missão ou compromisso para se atingir o objetivo do planejamento, definir políticas e critérios de trabalho, estabelecer metas, desenvolver um plano de ações necessárias para se atingir metas e cumprir missões e objetivos, estabelecer um sistema de monitoramento, controle e análise das ações planejadas, definir um sistema de avaliação sobre os dados controlados e, finalmente, prever a tomada de medidas para prevenção e correção quanto aos desvios que poderão ocorrer em relação ao plano. (Floriano, 2004:8)

O planejamento em nível local se torna peça absolutamente necessária no acompanhamento dos direitos humanos. Isso é visível a partir da constatação de que a proximidade do interespaço propicia condições reais de interpelações mais eficientes e mais duradouras entre o poder público e a sociedade. Para Ferreira (1979), o planejamento público se apresenta como um instrumento de participação da sociedade nos negócios de Estado, objetivando a planificação para melhor distribuir os produtos e serviços de interesse público de forma a pensar racionalmente o Estado e a sociedade na gestão da coisa pública.

O planejamento como está posto na esfera pública é bastante recente, data do século XX. Surgiu com as experiências da ex-União Soviética, em meados da década de 1920, e chegou à França, aos Países Nórdicos e depois à Ásia e à América Latina (Menezes e Jannuzzi, 2009). Acrescente-se que:

Rev. Adm. Pública - Rio de Janeiro 49(4):985-1009, jul./ago. 2015 
Em todos os casos, esteve ligado a uma compreensão do papel do Estado na transformação da sociedade burguesa (...) seria uma modalidade tecnicamente mais bem articulada, para realizar políticas públicas - econômicas, sociais, ambientais —, analisando explicitamente a estruturação política em que opera ou que representa. (Pedrão, 2002:26)

O poder público municipal recebeu competência para promover a melhoria da qualidade de vida da população por meio do atendimento das demandas sociais a partir do planejamento público. Isso está previsto, conforme expressa o caput do art. 30 da Constituição Federal de outubro de 1988. Compete aos municípios manter programas de educação, prestar serviços de atendimento à saúde, promover o adequado ordenamento territorial, mediante planejamento, e promover a proteção do patrimônio histórico e cultural local. Dessa forma, o município tem obrigação de ter uma estrutura administrativa voltada para a prestação dos serviços básicos da cidadania e deve usar o instituto do planejamento para organizar seu território, definir seus programas sociais, disponibilizar equipamentos e serviços públicos para a população (Bromley, 1982; Campos, 1980; Matus, 1997; Dowbor, 1998).

Os arts. 182 e 183 da Constituição Federal, regulamentados pela Lei ํo 10.257, de julho de 2001 — Estatuto da Cidade, deram elevada importância para a prática do planejamento. De acordo com Menezes e Jannuzzi (2009:72), "O Estatuto da Cidade caracteriza-se principalmente por uma orientação ética de forte posicionamento social, viabilizando intervenções no direito de propriedade do solo urbano por motivação do bem coletivo e social".

$\mathrm{O}$ art. 4º, III, e alíneas, da Lei no 10.257 estabelece:

Art. $4^{\circ}$ Para os fins desta Lei serão utilizados, entre outros instrumentos:

III - planejamento municipal, em especial;

a) plano diretor;

b) disciplina do parcelamento, do uso e da ocupação do solo;

c) zoneamento ambiental;

d) plano plurianual;

e) diretrizes orçamentárias e orçamento anual;

f) gestão orçamentária participativa;

g) planos, programas e projetos setoriais;

h) plano de desenvolvimento econômico e social.

Esses instrumentos devem nortear a gestão municipal quando da elaboração do planejamento. As orientações de diagnóstico devem ser aferidas mediante a ausência ou presença deles, em maior ou menor escala, sempre favorável ao desempenho positivo junto à população, assistida ou beneficiada pelas políticas públicas de um modo geral.

Acrescente-se, ainda, a importância de mecanismos de controle interno para que os objetivos previstos na administração sejam alcançados (Chiavenato, 2000). Para Franco e Marra (2001), controle interno é um conjunto de instrumentos destinados a vigilância, fiscalização e verificação administrativa, que favorecem o controle das ações que ocorrem no interior 
da empresa. Em termos da administração pública, cada município deve ter uma atividade responsável pelo controle interno (Cruz e Glok, 2008) como garantia, por exemplo, de que aspectos legais da administração estão sendo observados.

Por fim, o planejamento público viabiliza o presente, sem desprezar o que foi erro no passado. Segundo Toledo (2005), enquanto o planejamento é adotado na perspectiva de "pensar o futuro", a gestão consiste no agir, no executar. Para Teixeira (2004), no âmbito da administração pública a gestão pode ser definida como os meios pelos quais as metas de uma organização podem ser alcançadas e os recursos disponíveis, utilizados com efetividade. Nesses termos entende-se que uma boa gestão municipal requer a adoção de mecanismos institucionais capazes de fortalecer o processo de descentralização e municipalização pósConstituição Federal de 1988 e promover os direitos da população (Arretche, 2003).

Gershon e colaboradores (2005) argumentam que um arranjo institucional, com vistas a aumentar a eficácia e a efetividade das políticas de direitos humanos no município, depende de estruturas organizacionais compostas por instrumentos que facilitem a reflexão e a ação em torno dessa temática. Os esforços do município nesse sentido podem ser avaliados em três dimensões, como destaca Toledo (2005). Segundo a autora, a dimensão normativa inclui os instrumentos legais que respaldam a ação do município, a dimensão participativa permite verificar a existência de instâncias de participação da sociedade nas políticas de direitos humanos e a dimensão financeira refere-se à forma como os recursos financeiros são geridos e aplicados na gestão municipal.

Cada uma das dimensões demanda inovações nas formas de gestão. Tais inovações, segundo Farah (2003), correspondem a processos de mudanças na gestão pública no Brasil e, conforme Salgado (2005), são alternativas buscadas pelas administrações municipais para enfrentar o novo contexto de descentralização. Elas se materializam por meio da implementação de instrumentos de gestão que são mecanismos facilitadores da ação do poder local em face das suas novas competências.

A Pesquisa de Informações Básicas Municipais realizada pelo Instituto Brasileiro de Geografia e Estatística com o objetivo de traçar o perfil da gestão nos municípios brasileiros sistematiza os instrumentos de gestão municipal dos direitos humanos em cinco classes: i) Órgão Gestor; ii) Programas e Ações; iii) Conselhos Municipais de Direitos Humanos; iv) Direitos Humanos e Legislação Municipal; e v) Acessibilidade. A conexão entre essas classes é facilmente observada.

A existência de um órgão gestor ou estrutura específica para a implementção das políticas de direitos humanos é importante não só por seu valor simbólico como também pela possibilidade de lidar com recursos próprios, caso de uma secretaria dos direitos humanos. Segundo Gershon, Alto e Souza (2005), a secretaria municipal dos direitos humanos seria uma departamentalização formal de uma política de direitos humanos, fundamental para mostrar sua importância e consolidar seu processo de institucionalização.

A existência de programas e ações voltados para a promoção e garantia dos direitos da população reflete a responsabilidade e o compromisso do município com o atendimento de demandas sociais. É resultado, ainda, de processos históricos e de mobilização social. A 
participação da sociedade civil vem ganhando espaço cada vez maior nos processos de tomada de decisão governamentais. Apesar de existirem outros canais de participação popular como fóruns e orçamento participativo, os conselhos municipais são os instrumentos mais comuns na esfera local, atuando como instrumentos de democratização da gestão. Gershon, Alto e Souza (2005) acreditam que os conselhos municipais de direitos humanos cumprem a função de favorecer a absorção do tema pelas administrações locais. Eles são um importante instrumento de gestão, pois permitem a integração entre instâncias, especialmente no que diz respeito ao estreitamento das relações entre governo municipal e sociedade civil, assumindo dessa forma um protagonismo no cumprimento da agenda de direitos humanos, na articulação, controle, fiscalização e operacionalização das políticas públicas da temática.

Os conselhos municipais, assim como outros instrumentos de gestão municipal, estão legalmente amparados. Como argumenta Meirelles (1998), na administração pública só é permitido fazer o que a lei determina. Assim, uma boa gestão dos direitos humanos está condicionada a regras. Cada município é responsável por adotar instrumentos legais como leis, decretos e normativas que deverão reduzir a discriminação e reconhecer os direitos dos vulneráveis.

Adicionalmente, com base no Decreto Federal no 5.296/2004 que regulamenta as leis ํo 10.048/2000 e ํo 10.098/2000, cabe aos municípios promover a acessibilidade de pessoas com deficiência ou mobilidade reduzida, ou seja, cabe ao município favorecer as condições para que todos exerçam a cidadania de forma plena, o que envolve a construção de equipamentos como rampas de acesso, sanitários adaptados, telefones acessíveis, transporte públicos, sinalização de atendimento prioritário, entre outros.

Os instrumentos citados não exaurem as possibilidades de gestão municipal dos direitos humanos, as quais podem, inclusive, variar espacialmente. No entanto, ao implementá-los, o poder público local cria condições para que a população tenha o direito de ter acesso à justiça na reserva do possível para efetivação dos direitos humanos: econômicos, sociais e ambientais.

\section{Mecanismos de gestão dos direitos humanos nos municípios do Ceará}

Após mais de duas décadas da promulgação da Constituição Federal de 1988, a qual alavancou o processo de municipalização no Brasil, muitos municípios não se encontram aptos a exercer as competências que lhes foram atribuídas. Nota-se a fraqueza das instituições político-administrativas e organizações da sociedade (Frey, 1996) e a debilidade da gestão em diferentes áreas da administração pública. Essa realidade foi observada nos municípios do estado do Ceará, conforme estudos de Carvalho, Lima e Sousa (2013) e Lima e colaboradores (2014) nas áreas de saneamento básico e segurança pública, respectivamente. No entanto, não existem análises no âmbito dos direitos humanos.

A implementação de instrumentos básicos de gestão municipal no âmbito dos direitos humanos afeta a população em geral e, em especial, as pessoas vulneráveis (menores de ida- 
de, mulheres grávidas, idosos, homossexuais, pessoas com necessidades especiais). A vulnerabilidade dessas pessoas se traduz na dependência de políticas sociais e políticas públicas, que antes de significarem políticas distributivas, se destinam à promoção do acesso a condições precárias de subsistência. Com vistas a analisar a implementação dos mecanismos de gestão de direitos humanos nos municípios do Ceará foi definido o sistema de indicadores expresso no quadro 1. A seleção de indicadores é sempre um desafio. Dificuldades como disponibilidade e qualidade dos dados, fundamentação teórica frágil, baixa relevância das informações coletadas podem comprometer análises. Neste estudo buscou-se reduzir tais limitações de modo que as classes e indicadores foram definidos com base na sua pertinência quanto ao tema e qualidade das informações existentes. Assim, foram utilizadas literatura técnica e científica e base de dados oficial, publicada na Pesquisa de Informações Básicas Municipais, ano 2011, ${ }^{1}$ do Instituto Brasileiro de Geografia e Estatística (IBGE). Segundo Jannuzzi (2001), indicadores fornecidos por agências públicas estão entre as fontes mais confiáveis. Foram coletados dados referentes a cada indicador, para cada um dos 184 municípios cearenses.

Os indicadores foram organizados nas classes propostas pelo IBGE e já citadas anteriormente: i) Órgão gestor; ii) Programas e ações; iii) Direitos humanos e Legislação Municipal; iv) Conselhos Municipais de Direitos Humanos; e v) Acessibilidade.

Os indicadores buscaram refletir a condição do município quanto ao grau de implementação de mecanismos e ações voltados para a promoção dos direitos humanos.

\section{Quadro 1}

\section{Sistema de indicadores de gestão municipal dos direitos humanos}

\begin{tabular}{|l|l|}
\hline Dimensão & \multicolumn{1}{|c|}{ Indicadores de Gestão } \\
\hline & 1. Existência de órgão gestor da política de direitos humanos \\
& 2. Orçamento próprio para política de direitos humanos \\
3. Execução de programas e ações para ciganos & 4. Execução de programas e ações para crianças e adolescentes \\
Órgão Gestor & 5. Execução de programas e ações para mulheres \\
& 6. Execução de programas e ações para idosos \\
& 7. Execução de programas e ações para lésbicas, gays, bissexuais, travestis e transexuais \\
& 8. Execução de programas e ações para população em situação de rua \\
9. Execução de programas e ações para pessoa com deficiência \\
10. Execução de programas e ações para outros grupos \\
11. Órgão gestor não executa programas e ações para a promoção dos direitos humanos \\
\hline
\end{tabular}

Continua

\footnotetext{
${ }^{1}$ A Pesquisa de Informações Básicas Municipais traz um conjunto de indicadores organizados em seções. Essas seções variam de edição para edição. Os dados mais recentes referentes aos direitos humanos correspondem ao ano de 2011 (IBGE, 2012). Todos os indicadores apresentados no quadro 1 foram extraídos da planilha de dados disponibilizada pelo IBGE no endereço: <www.ibge.gov.br/home/estatistica/economia/perfilmunic/2011/defaulttabzip_xls.shtm>.
} 


\begin{tabular}{|c|c|}
\hline Dimensão & Indicadores de Gestão \\
\hline Programas e Ações & $\begin{array}{l}\text { 1. Programas ou ações de combate ao uso de trabalho forçado } \\
\text { 2. Programas ou ações de combate ao sub-registro civil de nascimento } \\
\text { 3. Programas ou ações para a população em situação de rua } \\
\text { 4. Programas ou ações para o enfrentamento a violência contra lésbicas, gays, bissexuais, } \\
\text { travestis e transexuais (LGBTT) } \\
\text { 5. Programas ou ações de reinserção de egressos do sistema prisional } \\
\text { 6. Programas ou ações de proteção de pessoas ameaçadas de morte } \\
\text { 7. Programas ou ações de educação em direitos humanos } \\
\text { 8. Programas ou ações de promoção de igualdade racial } \\
\text { 9. Política, programa ou ações para crianças e adolescentes } \\
\text { 10. Existência de plano municipal de atendimento socioeducativo } \\
\text { 11.Política, programa ou ações para pessoas com deficiência } \\
\text { 12.Política, programa ou ações para pessoas idosas }\end{array}$ \\
\hline $\begin{array}{c}\text { Direitos Humanos e Legisla- } \\
\text { ção Municipal }\end{array}$ & $\begin{array}{l}\text { 1. Existência de acampamento cigano } \\
\text { 2. Adaptação de espaços culturais, artísticos e desportivos para facilitar o ingresso, locomoção } \\
\text { e acomodação de pessoas com deficiência ou mobilidade reduzida } \\
\text { 3. Concessão de meia-entrada para maiores de } 65 \text { anos nos espetáculos culturais, artísticos } \\
\text { e eventos desportivos promovidos ou subsidiados pela administração pública } \\
\text { 4. Cotas para pessoas com deficiência no mercado de trabalho } \\
\text { 5. Ingresso de cães-guia para pessoas com deficiência visual em espaços culturais } \\
\text { 6. Punição à discriminação de lésbicas, gays, bissexuais, travestis e transexuais (LGBTT) } \\
\text { 7. Direitos de lésbicas, gays, bissexuais, travestis e transexuais } \\
\text { 8. Reconhecimento de nome social adotado por travestis e transexuais }\end{array}$ \\
\hline $\begin{array}{l}\text { Conselhos Municipais de } \\
\text { Direitos Humanos }\end{array}$ & $\begin{array}{l}\text { 1. Conselho municipal de direitos humanos } \\
\text { 2. Conselho municipal de direitos da criança e do adolescente } \\
\text { 3. Conselho tutelar } \\
\text { 4. Conselho municipal de igualdade racial ou similar } \\
\text { 5. Conselho municipal de direitos do idoso } \\
\text { 6. Conselho municipal de direitos da pessoa com deficiência } \\
\text { 7. Conselho municipal de direitos de lésbicas, gays, bissexuais, travestis e transexuais (LGBTT) } \\
\text { 8. Conselho municipal de políticas para mulheres } \\
\text { 9. Comitê gestor municipal para erradicação do sub-registro de nascimento }\end{array}$ \\
\hline Acessibilidade & $\begin{array}{l}\text { 1. Rampas de acesso } \\
\text { 2. Equipamento para deslocamento vertical } \\
\text { 3. Sanitário acessível } \\
\text { 4. Piso tátil } \\
\text { 5. Elevadores com braile e sonorizados } \\
\text { 6. Telefone público adaptado } \\
\text { 7. Mobiliário de recepção e atendimento adaptado } \\
\text { 8. Pessoal capacitado para prestar atendimento às pessoas com deficiência } \\
\text { 9. Área especial para (des)embarque para pessoa com deficiência } \\
\text { 10. Reserva de vaga para veículos que transportem pessoa com deficiência } \\
\text { 11. Sinalização atendimento prioritário } \\
\text { 12.Admissão de cão-guia } \\
\text { 13. Rampa externa }\end{array}$ \\
\hline
\end{tabular}

Fonte: Elaboração própria a partir de IBGE (2012). 
É importante ressaltar que, conforme IBGE (2010), a gestão dos direitos humanos nos municípios também se dá por meio de outros instrumentos, indiretamente e de forma transversal (instrumentos voltados à educação, saúde, segurança e outros).

A análise dos indicadores permitiu a identificação de contradições e omissão. A Constituição Federal brasileira atribui responsabilidades à União, estados, Distrito Federal e municípios no que diz respeito à promoção dos direitos humanos. Como explicitado no art. 23, incisos II e X, é competência do município juntamente com os demais entes federados:

II) cuidar da saúde e assistência pública, da proteção e garantia das pessoas portadoras de deficiências;

(...)

X) combater as causas da pobreza e os fatores de marginalização, promovendo a integração social dos setores desfavorecidos.

No entanto, a atuação dos municípios ainda é inexpressiva. A análise da frequência de instrumentos de gestão categorizados na classe "órgão gestor" mostra que em grande parte das cidades cearenses não há um órgão gestor específico para as políticas de direitos humanos. Apenas 54,7\% das prefeituras mantêm uma estrutura administrativa exclusiva para tratar das políticas direcionadas à garantia e proteção dos direitos da população. Em muitos municípios as intervenções nesse sentido costumam ocorrer de forma subordinada a outras secretarias, dado que a existência de um órgão gestor não significa a existência de uma secretaria específica e, muitas vezes, este encontra-se subordinado a alguma outra secretaria.

De fato, apesar de os instrumentos supranacionais de normatização dos direitos humanos apontarem a importância de secretarias como estruturas funcionais para reduzir custos e potencializar a produtividade das políticas, é comum que os direitos humanos sejam tratados de forma transversal a partir de ações implementadas pelas secretarias de educação, saúde, habitação. Considerando-se que, na metodologia adotada na Pesquisa de Informações Básicas Municipais do IBGE, o órgão gestor constitui-se nas estruturas administrativas instituídas para coordenação ou execução de políticas orientadas à realização de direitos de toda a população, as implicações dessa estrutura organizacional podem ser observadas na maior frequência na execução de ações e programas voltados para os grupos de idosos, crianças e adolescentes e pessoas com deficiência, público prioritário de tais secretarias, em relação às ações direcionadas a outros grupos de vulneráveis como ciganos e lésbicas, gays, bissexuais, travestis e transexuais (LGBTT). Assim, nota-se que a inexistência de um órgão gestor específico pode reduzir as chances de determinados grupos serem atendidos por políticas de seu interesse. Acrescente-se que a existência de uma secretaria traria como contribuição um orçamento próprio para as políticas locais de direitos humanos. 
Figura 1

\section{Frequência de ocorrência dos indicadores da dimensão órgão gestor nos municípios cearenses (2011)}

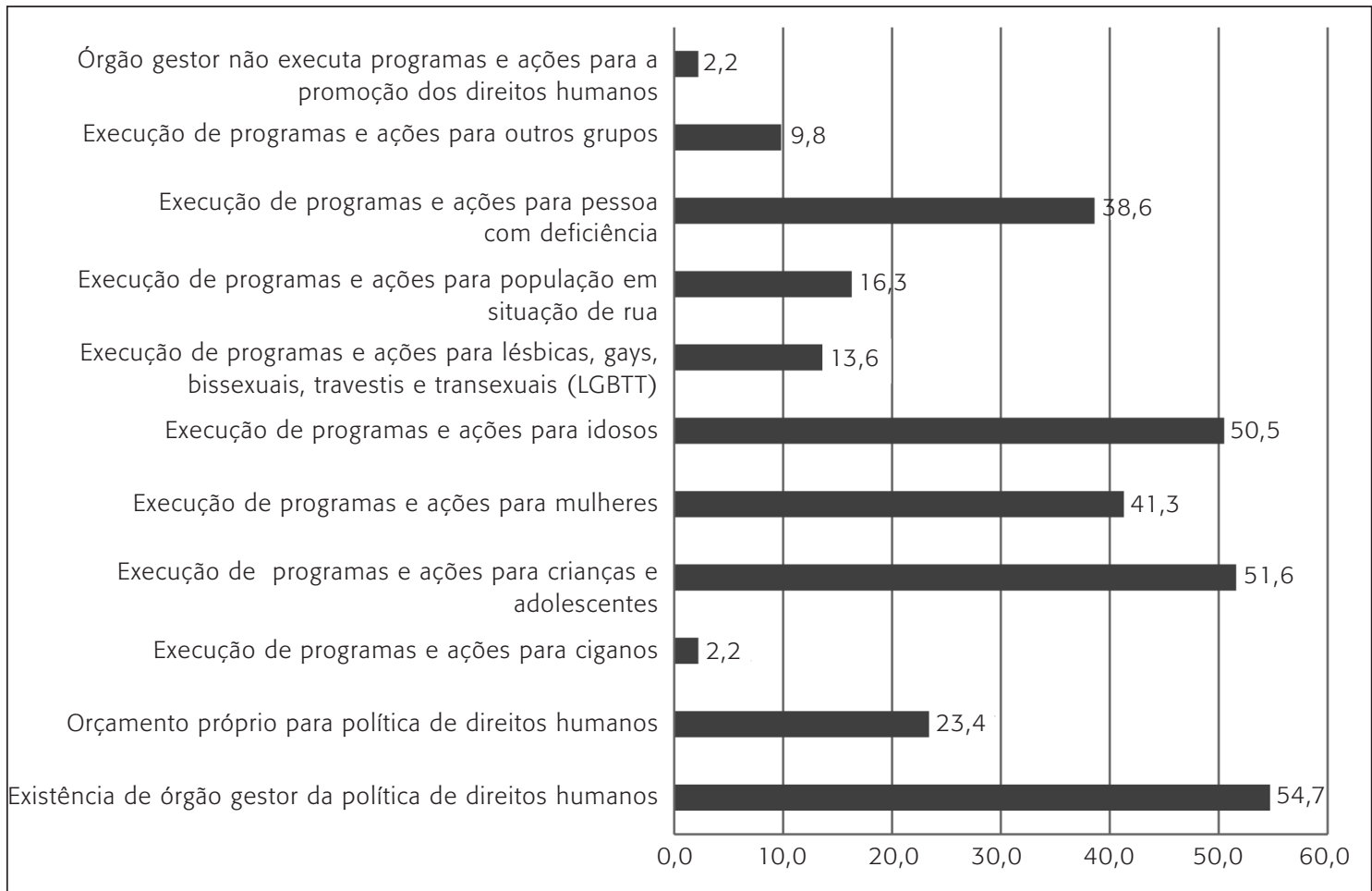

Fonte: Elaboração própria a partir de dados do IBGE.

Na Carta Magna brasileira o município está apto a adotar políticas e programas nas diferentes temáticas relacionadas aos direitos humanos. O papel do governo local nessa área é enfatizado, ainda, no $\S 12$ da Declaração de Istambul sobre Assentamentos Humanos, ${ }^{2}$ que o reconhece como de fundamental importância na implementação de ações voltadas para membros de grupos desfavorecidos e vulneráveis. No mesmo parágrafo é ressaltada a necessidade de

promover a descentralização através de autoridades legais democráticas e trabalhar para fortalecer suas capacidades financeiras e institucionais, de acordo com as condições dos países, ao mesmo tempo, garantindo sua transparência, responsabilidade e atendimento às necessidades do povo, que são exigências fundamentais para governos em todos os níveis.

\footnotetext{
${ }^{2}$ Elaborada durante a $2^{\text {a }}$ Conferência Mundial Sobre os Assentamentos Humanos - Habitat II, em Istambul, Turquia, 1996. Essa conferência produziu um Plano de Ação Global, a Agenda Habitat, que fornece diretrizes para a criação de assentamentos humanos sustentáveis durante o século XXI, tendo em conta sua relação com o meio ambiente, direitos humanos, desenvolvimento social, direitos das mulheres, questões demográficas e outros apêndices.
} 
O fortalecimento da capacidade financeira dos municípios no âmbito da gestão dos direitos humanos não é percebido entre as prefeituras cearenses. A inexistência de um orçamento próprio, fato que ocorre na maioria das prefeituras, limita a autonomia administrativa dado que o orçamento público define os gastos do governo e as políticas locais. Quando não há um orçamento específico para as políticas de direitos humanos, é aceitável presumir a inexistência de recursos para a execução de programas e ações nessa área e a omissão do poder público manifestada pela ausência de intervenções.

Os programas e ações voltados para a promoção dos direitos humanos encontram-se dispersos em estruturas administrativas fragmentadas impedindo o estabelecimento da equidade de tratamento a todos os segmentos da população. Essa condição se torna evidente nos municípios cearenses (figura 2). Existem grupos desassistidos por intervenções que deveriam favorecer seu processo de inclusão social. É o caso, por exemplo, dos egressos de sistemas prisionais. Observa-se, ainda, que, apesar da competência atribuída ao município no art. 23, inciso II da Constituição (citado anteriormente), 24,5\% dos municípios cearenses não possuem programas ou ações para pessoas com deficiência. Por outro lado, pessoas idosas, crianças e adolescentes encontram-se contempladas por algum tipo de programa ou ação em quase todos os municípios do Ceará. No entanto, como já discutido, essa parcela da população é beneficiada por programas e ações transversais implementados por órgãos de gestão da saúde e da educação.

\section{Figura 2}

Frequência de ocorrência dos indicadores da dimensão programas e ações nos municípios cearenses (2011)

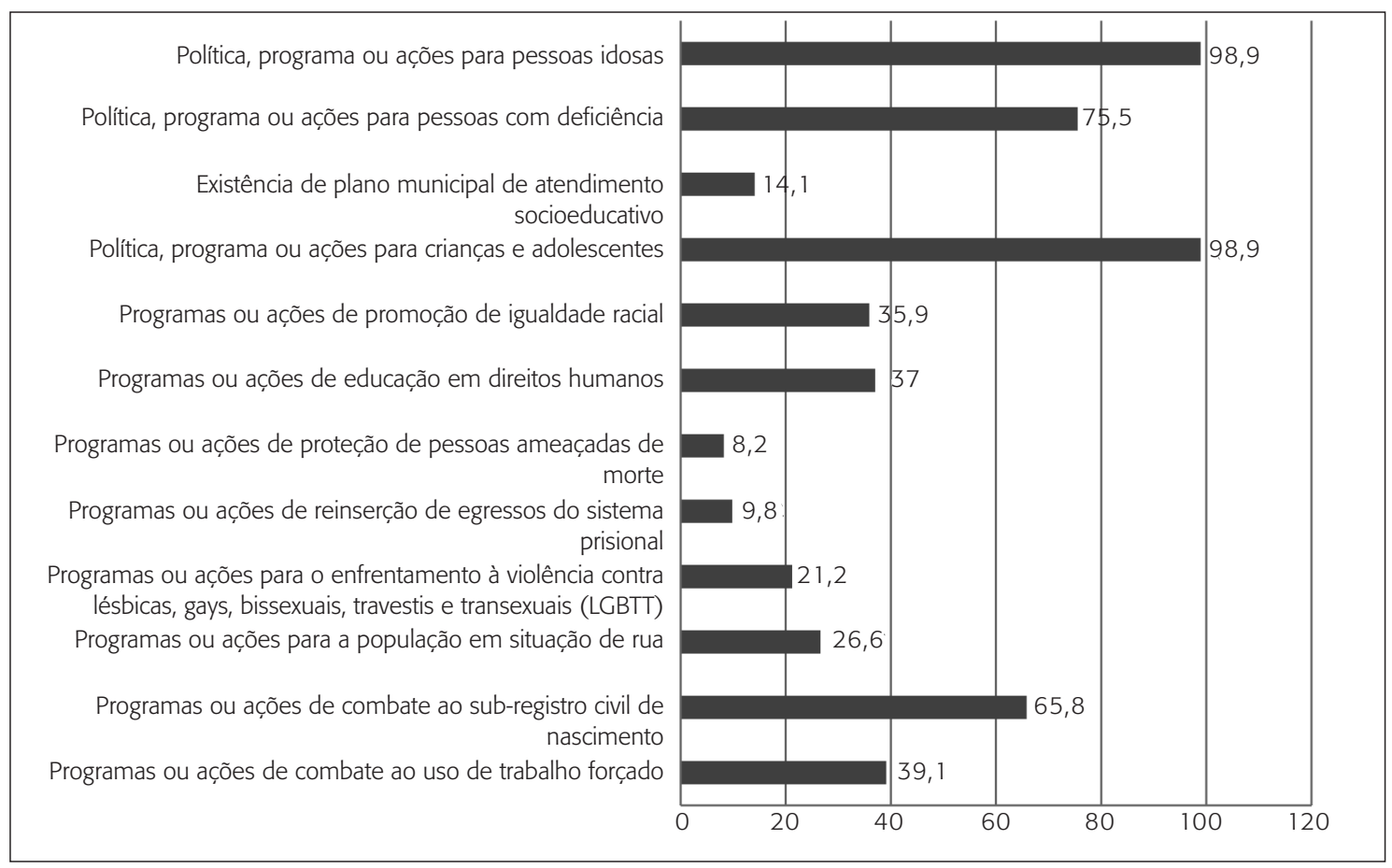

Fonte: Elaboração própria a partir de dados do IBGE. 
Para Saule Jr. (2001), essa configuração de gestão traz implicações negativas para as políticas públicas locais, uma vez que o primeiro pressuposto para as políticas públicas locais de direitos humanos é:

não aumentar a fragmentação e desarticulação existente na maioria dos Governos Locais entre as políticas setoriais referentes ao campo dos direitos econômicos, sociais e culturais. Constituir uma política pública local de direitos humanos não deve ser compreendido como mais uma política setorial como são, por exemplo, as áreas de educação, saúde, transporte, habitação, planejamento, obras e serviços, administração. A finalidade de constituir uma política pública local de direitos humanos é a de promover a integração e a articulação das políticas públicas setoriais. (Saule Jr., 2001:22)

O fortalecimento da democracia pressupõe o fortalecimento das instituições públicas locais. Os conselhos municipais colocam-se como uma estratégia de desenvolvimento e instrumento de democratização (Rocha, 2011). A importância dos Conselhos Municipais de Direitos Humanos na gestão municipal ampara-se em dois pontos principais: permitem que todos os cidadãos participem dos assuntos de interesse da comunidade e possibilitam o controle e a fiscalização das ações do Estado. Nessa perspectiva, a criação de Conselhos com a participação de representantes da sociedade civil, setor privado, governo, Ministério Público, Polícia, deve ser estimulada, especialmente em regiões do município onde ocorrem conflitos sociais (Saule Jr., 2001).

Apesar de ser uma condição para o recebimento de recursos financeiros por parte do governo federal, a existência de Conselhos Municipais na temática dos direitos humanos está vinculada a uma obrigatoriedade legal, ou seja, existe em função de alguma exigência e não a partir do interesse da população em participar da tomada de decisão. Isso é percebido no alto percentual de municípios que possuem Conselho Municipal de Direitos da Criança e Adolescente e Conselho Municipal de Direitos do Idoso. ${ }^{3}$ Por outro lado, nos casos que demandam apenas a mobilização da sociedade civil (Conselho Municipal de Direitos de LGBTT, Conselho Municipal de Igualdade Racial ou Similar e Conselho Municipal de Direitos Humanos) nota-se uma frequência menor.

Uma análise comparativa das figuras 2 e 3 sugere que nas áreas onde se verifica maior frequência de Conselhos Municipais se verifica, também, maior frequência de programas e ações voltados para os direitos humanos, o que corrobora a colocação de Gershon, Alto e Souza (2005) a respeito da importância dos Conselhos Municipais na implementação de Programas e Ações em áreas específicas dos direitos humanos.

\footnotetext{
${ }^{3} \mathrm{O}$ Estatuto da Criança e do Adolescente determina que todos os municípios devem constituir Conselhos Municipais dos Direitos da Criança e do Adolescente e Conselhos Tutelares. O Estatuto do Idoso, Lei no 10.741, de 1ㅇ de outubro de 2003, e a Política Nacional do Idoso, instituída pela Lei no 8.842, de 4 de janeiro de 1994, preveem a criação de Conselhos Municipais dos Direitos do Idoso e sua competência na supervisão, acompanhamento, fiscalização e avaliação da Política Nacional do Idoso (IBGE, 2012).
} 
Figura 3

Frequência de ocorrência dos indicadores da dimensão direitos humanos e legislação municipal nos municípios cearenses (2011)

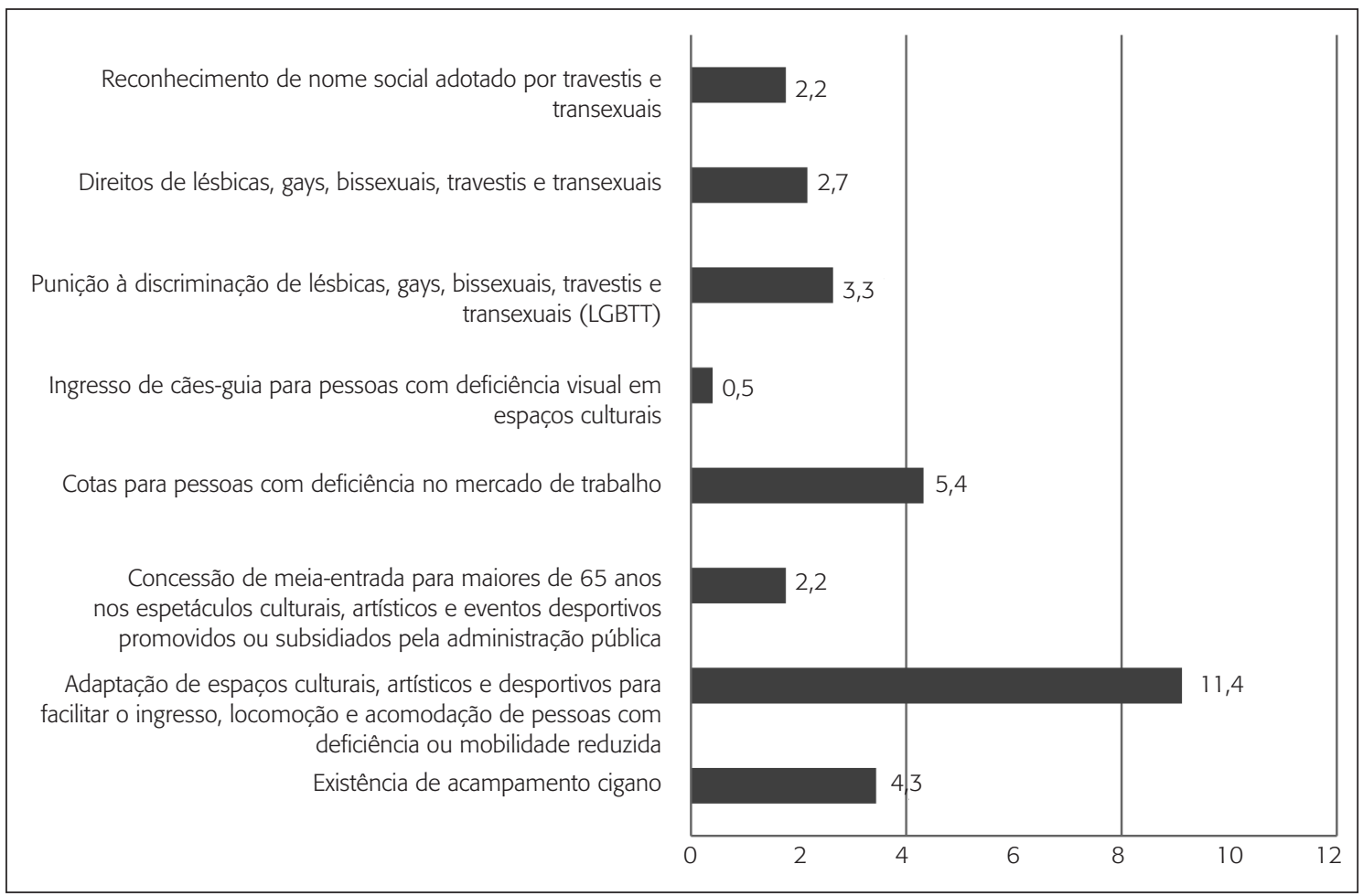

Fonte: Elaboração própria a partir de dados do IBGE.

A omissão da administração pública perante a implementação de políticas de direitos humanos para todos os vulneráveis é atribuída, por um lado, à falta de participação popular. Por outro lado, é inconteste que a fragilidade do aparato legal da gestão municipal dos direitos humanos limita a ação do poder público. O município, na sua atribuição de constituir políticas públicas que resguardem os direitos humanos, enfrenta desafios que demandam implementação e atualização de uma legislação que efetivamente proteja o cidadão. Nesse sentido, o município deve dispor em sua legislação de normas que reduzam a desigualdade e a discriminação que ameaçam a dignidade humana. A figura 4 apresenta temas que deveriam ser contemplados na legislação municipal. O percentual de municípios cearenses que possuem arcabouço jurídico para garantir e promover os direitos humanos é muito baixo.

A proporção de municípios que possui legislação que assegure o ingresso de cães-guia para pessoas com deficiência visual em espaços culturais ou a adaptação de espaços culturais, artísticos e desportivos para facilitar o ingresso, locomoção e acomodação de pessoas com deficiência ou mobilidade reduzida é insignificante. O mesmo se observa em relação aos instrumentos que poderiam reduzir a discriminação de LGBTT (legislação referente a punição à discriminação de lésbicas, gays, bissexuais, travestis e transexuais (LGBTT), direitos de lés- 
bicas, gays, bissexuais, travestis e transexuais e reconhecimento de nome social adotado por travestis e transexuais) ou melhorar a qualidade de vida de pessoas idosas e deficientes (concessão de meia-entrada para maiores de 65 anos nos espetáculos culturais, artísticos e eventos desportivos promovidos ou subsidiados pela administração pública e cotas para pessoas com deficiência no mercado de trabalho).

\section{Figura 4}

\section{Frequência de ocorrência dos indicadores da dimensão Conselhos Municipais de Direitos Humanos nos municípios cearenses (2011)}

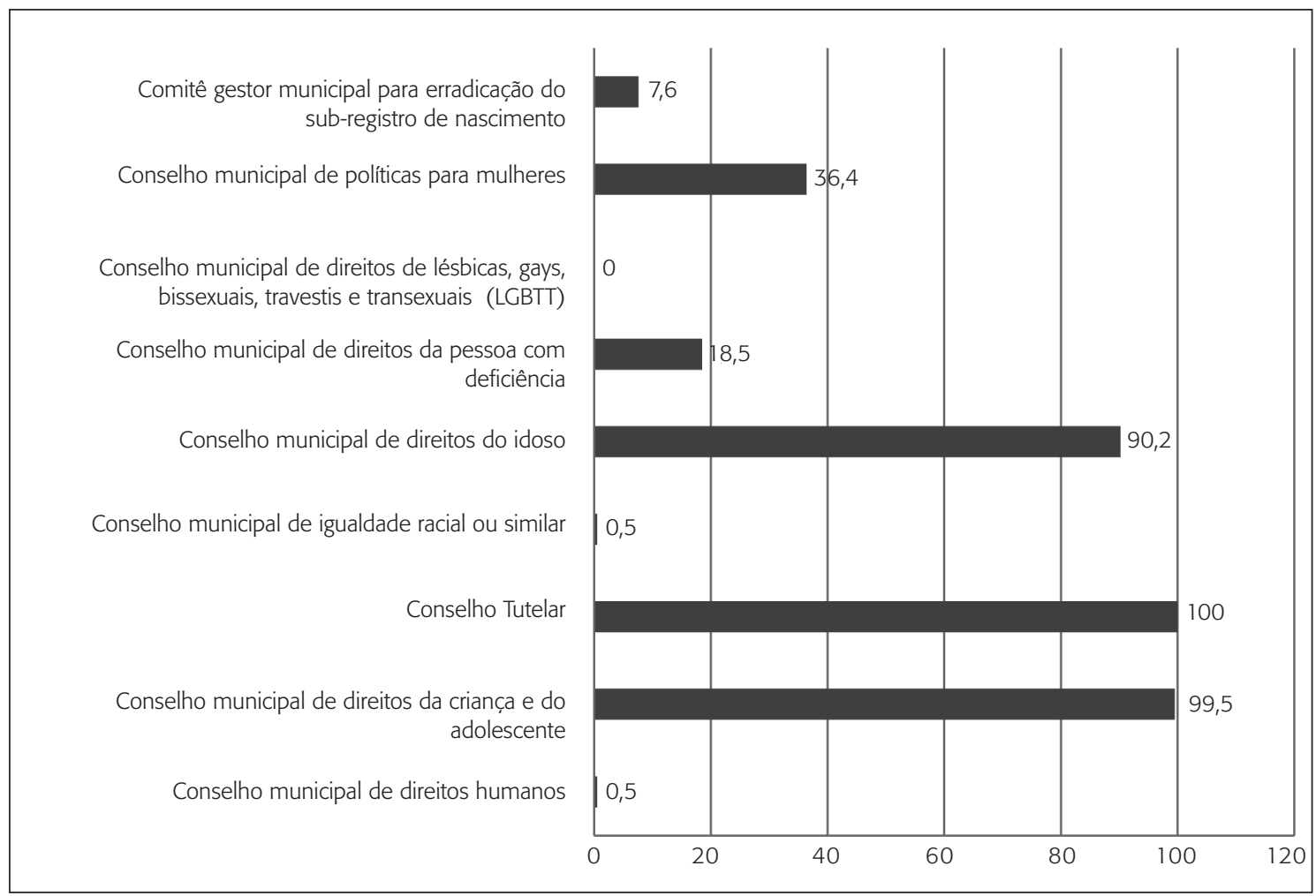

Fonte: Elaboração própria a partir de dados do IBGE.

A falta de uma legislação que assegure os direitos humanos nos municípios cearenses é acompanhada da escassez de medidas concretas quanto à implementação de equipamentos facilitadores da inclusão de pessoas com deficiência ou promotores da acessibilidade.

O reconhecimento da necessidade de medidas voltadas para a inclusão de pessoas com deficiência está implícito no Decreto no 5.296, de 2 de dezembro de 2004, Art. 8o, que define acessibilidade como:

condição para utilização, com segurança e autonomia, total ou assistida, dos espaços, mobiliários e equipamentos urbanos, das edificações, dos serviços de transporte e dos dispositivos, sistemas 
e meios de comunicação e informação, por pessoa portadora de deficiência ou com mobilidade reduzida. (art. 8o, Decreto no ${ }^{\circ}$ 5.296)

Apesar de datar de 2004, apenas em 2009 o direito brasileiro incorporou a Convenção Internacional sobre os Direitos das Pessoas com Deficiência por meio do Decreto no 6.949/2009, em 26 de agosto de 2009. As implicações decorrentes de tal decreto reforçam a obrigação do Estado de assegurar à pessoa com deficiência o acesso a equipamentos que favoreçam a sua inclusão social. Nesse sentido, cabe ao Estado providenciar "acesso ao meio físico, ao transporte, à tecnologia de informação, à comunicação e a todos os outros serviços em igualdade de condições com as pessoas sem deficiência." (IBGE, 2012:95).

Nos últimos anos são percebidas mudanças quanto à implementação de adaptações. No entanto, apesar da obrigatoriedade, as alterações são reduzidas mesmo em espaços públicos que deveriam servir de exemplo para demais segmentos da sociedade. A figura 5 apresenta 13 equipamentos que deveriam existir nas prefeituras, de modo a favorecer a acessibilidade de pessoas com algum tipo de deficiência. Como se observa, o percentual de municípios que utilizam tais equipamentos é muito baixo, independente se envolvem custo elevado (elevadores adaptados, piso tátil) ou não (sinalização de atendimento prioritário, área para (des) embarque, reserva de vagas para veículos de transporte de pessoas com deficiência).

Figura 5

Frequência de ocorrência dos indicadores da dimensão acessibilidade nos municípios cearenses (2011)

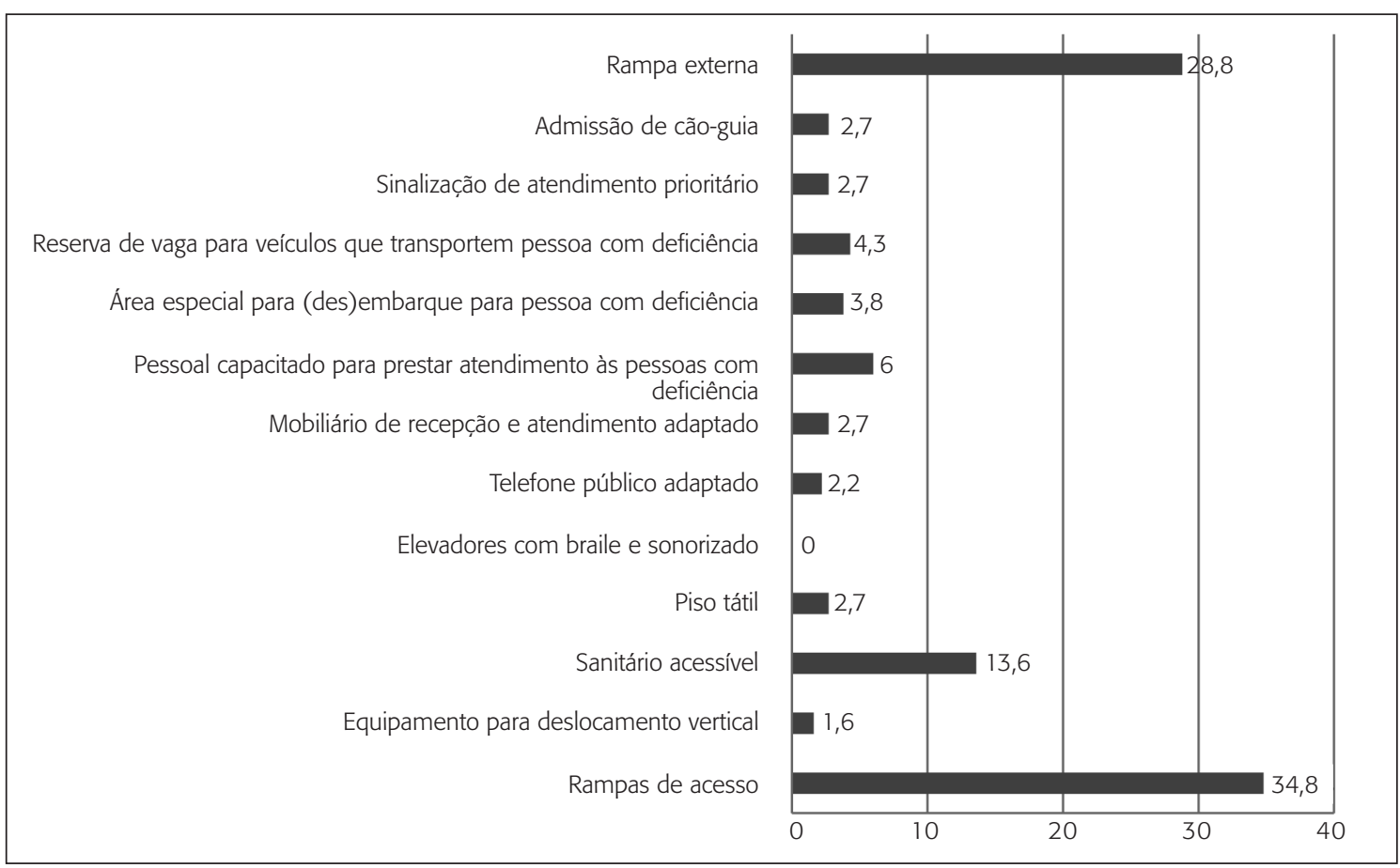

Fonte: Elaboração própria a partir de dados do IBGE. 
O emprego de um grande número de indicadores na avaliação da implementação de medidas administrativas e legislativas para a promoção e garantia dos direitos humanos no âmbito da administração pública municipal favorece a produção de informações úteis para captar a existência ou não do aparato institucional necessário a uma boa gestão municipal dos direitos humanos. No entanto, dificulta uma análise mais objetiva. Assim, optou-se por agregar as cinco dimensões apresentadas a fim de realizar uma avaliação global da situação dos municípios cearenses.

A agregação dos 53 indicadores em cinco subíndices, um para cada dimensão citada, e em seguida em um índice final: Índice de Implementação de Mecanismos de Gestão Municipal dos Direitos Humanos (IGMDH), seguiu uma lógica binária. Conforme adaptação de metodologia apresentada em Toledo (2005), o indicador recebeu escore 1 (um) quando observada a sua presença na gestão municipal e escore 0 (zero), em caso de sua ausência. A equação 1 permitiu o cálculo dos subíndices:

$$
I_{j h}=\frac{\sum_{i=1}^{m} E_{i j}}{\sum_{i=1}^{m} E_{\max i}} \times 100
$$

Sendo:

$\mathrm{I}_{\mathrm{jh}}=$ Subíndice observado no j-ésimo município referente à h-ésima dimensão da gestão municipal dos direitos humanos;

$\mathrm{E}_{\mathrm{ij}}=$ escore do i-ésimo indicador da h-ésima dimensão obtido pelo j-ésimo município;

$\mathrm{E}_{\text {maxi }}=$ escore máximo do i-ésimo indicador da $h$-ésima dimensão;

$\mathrm{i}=1, \ldots, \mathrm{m}$, representa os indicadores da $h$-ésima dimensão (dimensão órgão gestor $\mathrm{m}=11$; dimensão programas e ações $\mathrm{m}=12$; dimensão direitos humanos e legislação municipal $\mathrm{m}=8$; dimensão conselhos municipais de direitos humanos $\mathrm{m}=9$; e dimensão acessibilidade $\mathrm{m}=13$ ); $\mathrm{j}=1, \ldots, \mathrm{n}$, representa os municípios do Ceará ( $\mathrm{n}=184$ municípios);

$\mathrm{h}=1, \ldots, \mathrm{k}$, representa as dimensões do Índice de Implementação de Mecanismos de Gestão Municipal dos Direitos Humanos (IGMDH) ( $\mathrm{k}=5$ dimensões: dimensão órgão gestor, dimensão programas e ações, dimensão direitos humanos e legislação municipal, dimensão conselhos municipais de direitos humanos e dimensão acessibilidade).

Por fim, considerando-se um nível global agregando todas as dimensões, foi calculado o Índice de Implementação de Mecanismos de Gestão Municipal dos Direitos Humanos (IGM$\mathrm{DH})$, de acordo com a equação 2 . 


$$
I G M D H_{j}=\sum_{i=1}^{p} \frac{\mathrm{E}_{\mathrm{ij}}}{\operatorname{Emax}_{\mathrm{ij}}} \times 100
$$

Sendo:

$\mathrm{IGMDH}_{\mathrm{j}}=$ Índice de Implementação de Mecanismos de Gestão Municipal dos Direitos Humanos (IGMDH) do j-ésimo município,

$\mathrm{i}=1, \ldots ., \mathrm{p}$, representa todos os indicadores avaliados $(\mathrm{p}=53$ indicadores $)$

Após o cálculo do $\mathrm{IGMDH}_{\mathrm{j}}$ para cada município obteve-se, por meio de média aritmética, o IGMDH para o estado do Ceará:

$I G M D H=\sum_{j=1}^{184} I G M D H_{j}$

184

$\mathrm{I}_{\mathrm{jh}}, \mathrm{IGMDH}_{\mathrm{j}}$ e IGMDH podem variar de 0 (zero) a 100 (cem). Quanto mais próximo de 100, maior o nível de implementação de mecanismos e ações de gestão municipal voltados para a promoção dos direitos humanos. Podem ser interpretados como a proporção de instrumentos de gestão avaliados que foi implementada pelo município. É necessário ressaltar que o IGMDH não teve a pretensão de qualificar a gestão dos direitos humanos nos municípios cearenses, mas hierarquizar e comparar os municípios de acordo com a implementação dos instrumentos de gestão, o que, em primeira instância, constitui o passo inicial para a criação de condições necessárias à prática de uma gestão eficiente dos direitos humanos.

Os resultados apresentados na tabela 1 permitem uma síntese da implementação de instrumentos de gestão municipal dos direitos humanos no Ceará, considerando-se os instrumentos avaliados. A primeira coluna apresenta, em termos médios, a proporção de instrumentos implementados pelos municípios cearenses. Assim, nota-se que os municípios adotam, em média, 25\% dos 53 instrumentos avaliados. Considerando-se as classes temáticas individualmente, nota-se que o melhor desempenho da gestão municipal na implementação de instrumentos se dá na existência de programas e ações voltados para os direitos humanos dado que, do total de 12 instrumentos avaliados na referida classe, uma média de 44,2\% é implementada pelos municípios. Esse percentual, apesar de ser o maior observado, é muito baixo e corrobora a colocação de Frey (1996) sobre a fraqueza das instituições político-administrativas. A maior deficiência na gestão municipal foi observada na classe Direitos Humanos e Legislação Municipal. Apenas 4\% dos instrumentos avaliados foram identificados na legislação local.

A análise por quartis permite a estratificação dos resultados. O terceiro quartil corresponde ao percentual de implementação de instrumentos de gestão que separa 75\% dos municípios com menores níveis de implementação dos 25\% com maiores níveis. Logo, tem-se que 
75\% dos municípios cearenses não implementaram nenhum dos instrumentos avaliados na sua legislação municipal. E ainda, em 75\% dos municípios cearenses o máximo percentual de implementação de instrumentos da classe Acessibilidade é de apenas 15,4\%. Apesar dos baixos níveis de implementação de instrumentos de gestão municipal observados nos municípios em geral, existem destaques pontuais, como se observa na coluna de máximo valor observado. No município de Irauçuba, 90,9\% dos instrumentos avaliados na classe Órgão Gestor foram implementados e em Limoeiro do Norte observou-se a implementação de todos os instrumentos incluídos na classe Programas e Ações.

\section{Tabela 1}

Estatísticas descritivas dos índices de gestão municipal dos direitos humanos no estado do Ceará, por dimensão e índice global. 2011. (\%)

\begin{tabular}{|lcccccc|}
\hline \multicolumn{1}{|c}{ Dimensões avaliadas } & Média & $\begin{array}{c}\text { Primeiro } \\
\text { quartil }\end{array}$ & $\begin{array}{c}\text { Segundo } \\
\text { quartil }\end{array}$ & $\begin{array}{c}\text { Terceiro } \\
\text { quartil }\end{array}$ & $\begin{array}{c}\text { Máximo valor } \\
\text { observado }\end{array}$ & $\begin{array}{c}\text { Coeficiente de } \\
\text { variação }\end{array}$ \\
\hline $\begin{array}{l}\text { Órgão gestor } \\
\text { Programas e ações }\end{array}$ & 27,6 & 0,0 & 27,3 & 54,5 & 90,9 & 99,7 \\
$\begin{array}{l}\text { Direitos humanos e legislação } \\
\text { municipal }\end{array}$ & 44,2 & 33,3 & 41,7 & 58,3 & 100,0 & 43,4 \\
$\begin{array}{l}\text { Conselhos Municipais de Direitos } \\
\text { Humanos }\end{array}$ & 4,0 & 0,0 & 0,0 & 0,0 & 62,5 & 213,9 \\
$\begin{array}{l}\text { Acessibilidade } \\
\text { Índice de Gestão Municipal dos }\end{array}$ & 25,3 & 33,3 & 33,3 & 44,4 & 66,7 & 26,1 \\
Direitos Humanos (IGMDH) & 25,0 & 18,9 & 24,5 & 30,2 & 61,5 & 126,0 \\
\end{tabular}

Fonte: Elaboração própria a partir de dados do IBGE.

Como pode ser observado, por meio do coeficiente de variação, há uma elevada heterogeneidade entre os municípios cearenses quanto aos subíndices e IGMDH. No entanto, por meio do emprego da técnica multivariada de análise de agrupamento ${ }^{4}$ foi possível classificar os municípios em três grupos homogêneos:

v 5,4 $\leq$ IGMDH $\leq$ 20,8 - municípios com níveis mais baixos de implementação de mecanismos e ações de gestão municipal voltados para a promoção dos direitos humanos

จ 22,6 $\leq$ IGMDH $\leq 34,0$ - municípios com níveis intermediários de implementação de mecanismos e ações de gestão municipal voltados para a promoção dos direitos humanos

、 35,8 $\leq$ IGMDH $\leq$ 56,6 - municípios com níveis mais elevados de implementação de mecanismos e ações de gestão municipal voltados para a promoção dos direitos humanos

\footnotetext{
${ }^{4}$ Segundo Hair e colaboradores (2005), análise de agrupamento é o nome dado a um grupo de técnicas multivariadas cuja finalidade primária é identificar e agregar observações com base em características semelhantes ou diferentes entre os grupos. Neste estudo foi adotado o método não hierárquico (K-médias).
} 
Essa classificação inclui apenas valores de IGMDH observados entre os 184 municípios. O limite inferior da primeira classe $(5,4)$ corresponde ao município com menor IGMDH e o valor superior da terceira classe $(56,6)$, ao município com maior IGMDH.

Considerando-se os grupos estabelecidos, optou-se por caracterizá-los a partir de indicadores sociais. A segmentação adotada sugere que nos municípios onde há maiores níveis de implementação de instrumentos de gestão municipal de direitos humanos há, também, melhores indicadores sociais. Comparando-se os três grupos, aquele formado pelos municípios com IGMDH entre 35,8 e 55,6 - maiores níveis de implementação de instrumentos de gestão dos direitos humanos - apresenta, em termos médios, menor taxa de mortalidade infantil, menor proporção de pessoas vulneráveis à pobreza, maior proporção de empregos formais e maior Índice de Desenvolvimento Municipal.

Tabela 2

Indicadores médios observados nos municípios com diferentes níveis de adoção de mecanismos e ações de gestão municipal voltados para a promoção dos direitos humanos no estado do Ceará (2010)

\begin{tabular}{|c|c|c|c|}
\hline Classes & $5,4 \leq \mathrm{IGMDH} \leq 20,8$ & $22,6 \leq \mathrm{IGMDH} \leq 34,0$ & $35,8 \leq \mathrm{IGMDH} \leq 56,6$ \\
\hline Número de municípios & 73 & 85 & 26 \\
\hline $\begin{array}{l}\text { Índice Gestão Municipal dos Direitos Humanos } \\
(2011)\end{array}$ & 16,23 & 27,48 & 41,58 \\
\hline $\begin{array}{l}\text { Mortalidade até } 5 \text { anos de idade (por mil crianças } \\
\text { nascidas vivas) }\end{array}$ & 27,62 & 26,20 & 24,61 \\
\hline Índice de Gini & 0,53 & 0,52 & 0,53 \\
\hline \% de vulneráveis à pobreza & 69,85 & 67,34 & 64,10 \\
\hline \% de crianças vulneráveis à pobreza & 84,60 & 82,27 & 78,48 \\
\hline $\begin{array}{l}\text { Grau de formalização dos ocupados - } 18 \text { anos ou } \\
\text { mais (\%) }\end{array}$ & 23,73 & 25,47 & 32,14 \\
\hline $\mathrm{IDH}-\mathrm{M}$ & 0,61 & 0,62 & 0,63 \\
\hline IDHM - Educação & 0,54 & 0,56 & 0,57 \\
\hline IDHM - Longevidade & 0,76 & 0,76 & 0,77 \\
\hline IDHM - Renda & 0,55 & 0,56 & 0,58 \\
\hline
\end{tabular}

Fonte: Elaborada a partir de IBGE (2011) e Pnud (2013).

Esse resultado não é suficiente para estabelecer uma relação significativa entre variáveis ou uma relação de causalidade entre a adoção de instrumentos de gestão municipal dos direitos humanos e indicadores socioeconômicos, mas reforça a necessidade de um posicionamento mais contundente das prefeituras quanto à inclusão da gestão dos direitos humanos na agenda municipal no Ceará. A omissão municipal na gestão pública cearense também foi observada em Carvalho, Lima e Sousa (2013) e Lima e colaboradores (2014). 


\section{Considerações finais}

As mudanças ocorridas a partir da reforma administrativa e da Constituição Federal - Constituição cidadã, como ficou conhecida - têm legado à sociedade e ao Estado uma ampla mudança nos rumos da gestão pública. O estudo mostrou, no entanto, que a gestão nos municípios cearenses ainda não se encontra instrumentalizada o suficiente para favorecer a atuação do poder local na promoção dos direitos humanos.

Os municípios adotam um comportamento omisso parecendo tratar o tema de forma transversal, fato percebido pelo baixo percentual de prefeituras com órgão gestor específico de direitos humanos. Ao assumir essa postura, o poder local, como unidade administrativa mais próxima dos cidadãos, reduz a sua atuação na promoção dos direitos de grupos vulneráveis e do desenvolvimento local. Por outro lado, a participação da população, avaliada aqui pela existência de Conselhos Municipais de Direitos Humanos, ainda é pequena, o que contribui para a manutenção do cenário observado.

Por fim, as implicações socioeconômicas da adoção de instrumentos de gestão municipal dos direitos humanos parecem ser abrangentes. Nessa perspectiva, como explicar a omissão dos municípios na implementação de tais instrumentos? A resposta foge ao escopo deste estudo, mas é colocada aqui como sugestão de pesquisas futuras.

\section{Referências}

ALVES, Arlete M. da S.; VASCONCELLOS, Luiz G. F. Desenvolvimento local e gestão municipal. Sociedade \& Natureza, v. 32, n. 32, p. 15-26, 2005.

ARRETCHE, Marta. Financiamento federal e gestão local de políticas sociais: o difícil equilíbrio entre regulação, responsabilidade e autonomia. Cien. Saúde Colet, v. 8, n. 2, p. 331-345, 2003.

BROMLEY, Ray. O processo do planejamento: lições do passado e um modelo para o futuro. In: BROMLEY, Ray; BUSTELO, Eduardo S. (Org.). Política $\times$ técnica de planejamento: perspectivas críticas. Brasília: Brasiliense e Unicef, 1982. p. 123-131.

CAMPOS, Ana M. Um novo modelo de planejamento para uma nova estratégia de desenvolvimento. Rev. Adm. Pública, v. 14, n. 3, p. 27-45, 1980.

CARVALHO, Ana C. de; LIMA, Patrícia V. P. S.; SOUSA, Rennaly P. A gestão municipal do saneamento básico no estado do Ceará. In: ENCONTRO REGIONAL DA SOBER: PLURALIDADES ECONÔMICAS, SOCIAIS E AMBIENTAIS: INTERAÇÕES PARA REINVENTAR O NORDESTE RURAL, VIII, 2013, Parnaíba.

CHIAVENATO, Idalberto. Introdução à teoria geral da administração. 6. ed. Rio de Janeiro: Campus, 2000 .

CONSTITUIÇÃO da República Federativa do Brasil. Brasília, DF: Senado Federal, 1988. 
CRUZ, Cláudia et al. Transparency of the municipal public management: a study from the homepages of the large Brazilian municipalities. Rev. Adm. Pública, v. 46, n. 1, p. 153-176, 2012.

CRUZ, Flavio da; GLOK, José O. Controle interno nos municípios: para a implantação e relacionamento com os tribunais de contas. 3. ed. São Paulo: Atlas, 2008.

DOWBOR, Ladislau. A reprodução social: propostas para uma gestão descentralizada. 2. ed. Petrópolis: Vozes, 1998.

FARAH, Marta F. dos S. Inovações e governo local no Brasil contemporâneo. In: FUNDAÇÃO GETULIO VARGAS. Programa Gestão Pública e Cidadania. Oficina de avaliação em políticas públicas. São Paulo: Fundação Getulio Vargas, 2003. p. 12-43.

FERREIRA, Francisco. W. Planejamento sim e não: um modo de agir num mundo em permanente mudança. Rio de Janeiro: Paz e Terra, 1979.

FIORILLO, Celso A. P. Curso de direito ambiental brasileiro. 6. ed. ampl. São Paulo: Saraiva, 2005. FLORIANO, Eduardo P. Planejamento ambiental. Santa Rosa: Anorgs, 2004. (Caderno didático, 6). FRANCO, Hilário; MARRA, Ernesto. Auditoria contábil. Normas de auditoria, procedimentos e papéis de trabalho, programas de auditoria, relatórios de auditoria. 4. ed. São Paulo: Atlas, 2001.

FREY, Klaus. Crise do Estado e estilos de gestão municipal. Lua Nova - Revista de Cultura e Política, São Paulo, n. 37, p. 107-251, 1996.

GERSHON, Débora; ALTO, Maurício A.; SOUZA, Rosimere. Gestão pública municipal e direitos humanos. Rio de Janeiro: Ibam/DES, 2005.

HAIR JR., Joseph. F. et al. Análise multivariada de dados. 5. ed. Porto Alegre: Bookman, 2005.

IBGE. Instituto Brasileiro de Geografia e Estatística. Censo demográfico 2010. Características da população e dos domicílios: resultados do universo. Rio de Janeiro: IBGE, 2011. Disponível em: <www.ibge.gov.br/home/estatistica/populacao/censo2010/caracteristicas_da_populacao/resultados_do_universo.pdf $>$. Acesso em: 24 mar. 2014.

IBGE. Instituto Brasileiro de Geografia e Estatística. Perfil dos municípios brasileiros - 2009. Pesquisa de informações básicas municipais. Coordenação de população e indicadores sociais. Rio de Janeiro: IBGE, 2010.

IBGE. Instituto Brasileiro de Geografia e Estatística. Perfil dos municípios brasileiros - 2011. Pesquisa de informações básicas municipais. Coordenação de população e indicadores sociais. Rio de Janeiro: IBGE, 2012.

JANNUZZI, Paulo de M. Indicadores sociais no Brasil: conceitos, fontes de dados e aplicações. São Paulo: Alínea, 2001.

LIMA, Patrícia V. P. S. et al. Gestão municipal da segurança pública: responsabilidade dos municípios brasileiros no combate à violência. Revista Políticas Públicas, São Luís, v. 18, n. 2, p. 399-414, 2014.

MATUS, Carlos. Política, planejamento e governo. 3. ed. Brasília: Ipea, 1997.

Rev. Adm. Pública - Rio de Janeiro 49(4):985-1009, jul./ago. 2015 
MEIRELLES, Hely L. Direito municipal brasileiro. 11. ed. atual. por Célia Prendes e Marcio S. Reis. São Paulo: Malheiros, 1998.

MENEZES, Luiz C. A.; JANNUZZI, Paulo de M. Planejamento nos municípios brasileiros: um diagnóstico de sua institucionalização e seu grau de efetividade. In: VITTE, Claudete C. S.; KEINERT, Tânia M. M. Qualidade de vida, planejamento e gestão urbana: discussões teórico-metodológicas. Rio de Janeiro: Bertrand Brasil, 2009.

MOREIRA, José C. B. Temas de direito processual. São Paulo: Saraiva, 1977.

OLIVEIRA, Helena. A VI Conferência Nacional de Direitos Humanos, as políticas públicas e os desafios para o município. Revista de Administração Municipal - Municípios, Rio de Janeiro, v. 46, n. 232, p. 11-16, 2001.

PEDRÃO, Fernando. O planejamento socialmente necessário. Análise e Dados, Salvador, v. 12, n. 2, p. 23-26, 2002.

PIOVESAN, Flávia. Direitos humanos e o direito constitucional internacional. 5. ed. São Paulo: Max Limonad, 2002.

PNUD. Programa das Nações Unidas para o Desenvolvimento; IPEA. Instituto de Pesquisa Econômica Aplicada, FJP. Fundação João Pinheiro. Atlas do desenvolvimento humano no Brasil 2013. Rio de Janeiro: Ipea, 2013. Disponível em: <www.atlasbrasil.org.br/2013//>. Acesso em: 24 jan. 2014.

ROCHA, Carlos V. Gestão pública municipal e participação democrática no Brasil. Revista de Sociologia e Política, v. 19, n. 38, p. 171-185, 2011.

SALGADO, Silvia R. da C. Administração municipal: a comunicação e a informação pública inovando a gestão das políticas sociais. Tese (doutorado) - Escola de Comunicações e Artes. Universidade de São Paulo, São Paulo, 2005.

SARLET, Ingo W. A eficácia dos direitos fundamentais. 2. ed. Porto Alegre: Livraria do Advogado, 2001.

SAULE JR., Nelson. Políticas públicas locais - município e diretos humanos. In: BUCCI, Maria P. D. et al. (Org.). Direitos humanos e políticas públicas. São Paulo: Pólis, 2001. (Cadernos Pólis, 2).

SILVA, José A. Curso de direito constitucional positivo. 9. ed. São Paulo: Malheiros, 1992.

TEIXEIRA, Antônio A. O uso das novas tecnologias de informação e comunicação e as informações públicas nas gestões municipais: o caso do estado do Ceará, Brasil. In: CONGRESO ONLINE DEL OBSERVATORIO PARA LA CIBERSOCIEDAD, II, 2004. Disponível em: <www.cibersociedad.net/ congres2004/grups/fitxacom_publica2.php?idioma=en\&id=648\&grup=94>. Acesso em: $24 \mathrm{dez}$. 2014.

TOLEDO, Silvia R. B. de. Indicadores da capacidade de gestão ambiental urbana dos governos locais nas cidades médias do estado de São Paulo. Dissertação (mestrado em geografia) — Universidade Estadual de Paulista, Rio Claro, 2005. Disponível em: <www.cepam.sp.gov.br/arquivos/artigos/ dissertacao_bio.pdf>. Acesso em: 24 dez. 2014. 
VAZ, Anderson R. A cláusula da reserva do financeiramente possível como instrumento de efetivação planejada dos direitos humanos, econômicos, sociais e culturais. Revista de Direito Constitucional e Internacional, v. 17, n. 66, p. 25-48. jan./mar. 2009.

Magda Cristina de Sousa é doutoranda em desenvolvimento e meio ambiente na Universidade Federal do Ceará (UFC). Professora adjunta da Universidade Federal Rural do Semiárido (Ufersa) — Filosofia e Direito. E-mail: mzdsousa@hotmail.com.

Patrícia Verônica Pinheiro Sales Lima é professora associada da Universidade Federal do Ceará (UFC). Programas de Pós-Graduação em Desenvolvimento e Meio Ambiente e Economia Rural. Doutora em economia aplicada. Bolsista de produtividade CNPq. E-mail: pvpslima@gmail.com.

Ahmad Saeed Khan é professor titular da Universidade Federal do Ceará (UFC). Programas de PósGraduação em Desenvolvimento e Meio Ambiente e Economia Rural. Ph.D em economia. Bolsista de produtividade CNPq. E-mail: saeed@ufc.br. 
